Milano, Ilarino da, „Il Liber supra stella del piacentino Salvo Burci contro i Catari e altre correnti ereticali“, Aevum 16 (1942), 272-319.

Patschovsky, Alexander, Der Passauer Anonymus. Ein Sammelwerk über Ketzer, Fuden, Antichrist aus der Mitte des 13. Jahrhunderts, Stuttgart 1968.

Wakefield, Walter, „Notes on some Antiheretical Writings of the Thirteenth Century“, Franciscan Studies 27 (1967), 285-321, hier 297-299.

Wessley, Stephen, „The composition of Georgius' Disputatio inter Catholicum et paterinum hereticum", Archivum fratrum Praedicatorum 48 (1978), 55-61.

\title{
Überlieferung:
}

Der Text ist reich überliefert. Die Herausgeberin der kritischen Ausgabe, C. Hoécker, hat 53 Handschriften beschrieben und untersucht (Auflistung 81-82, Beschreibung der Handschriften LXXVII-GLI).

\section{R14. Anonymus / Moneta Cremonensis OP, † um 1260}

De sacramento eucharistiae

Studie: Kapitel 3.2.

Titel: Die Schrift trägt in der einzigen Handschrift, die sie als eigenständigen Text überliefert, Clermont-Ferrand, BM, 153, den Titel De sacramento eucharistiae.

Incipit: Haereticus: Quomodo potest hoc esse, quod panis aut vinum convertatur in corpus Christi aut sanguinem?...

Explicit:... in ore duorum vel trium testium stabit omne verbum.

Autor und Datierung: Die Schrift besteht aus Auszügen der Summa des Moneta von Cremona (verfasst ca. 1241), die in Dialogform umgearbeitet wurden, um so die Disputatio inter Catholicum et Paterinum hereticum inhaltlich zu ergänzen. Nur in dem Codex aus Clermont-Ferrand wird sie als eigenständige Schrift nach der Disputatio überliefert, ansonsten bildet sie in allen Handschriften der französischen Redaktion der Disputatio inter Catholicum et Paterinum das 8. Kapitel (siehe R13 - Fassungen). De sacramento muss zwischen 1241 und der Niederschrift der ältesten Handschrift im 14. Jh. entstanden sein. Hoécker vermutet eine Entstehung Anfang des 14. Jhs., als die Disputatio in Frankreich Sammelhandschriften für Inquisitoren beigefügt wurde. Für den praktischen Gebrauch sei dann, so Hoécker, eine Behandlung des Fragenkomplexes

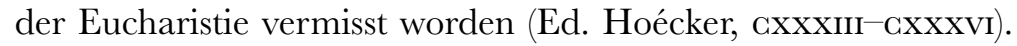

Moneta de Cremona, Inquisitor in der Lombardei, verfasste eine Summa adversus Catharos et Valdenses. In dieses Werk ließ er seine 